\title{
RE-ENTANGLING DESIGN AND SCIENCE FICTION: THE CASE OF DALEKO
}

\author{
EDUARDO HARRY LUERSEN*
}


INTERNATIONAL JOURNAL OF FILM AND MEDIA ARTS (2021) Vol. 6, №. 1

\section{Eduardo Harry Luersen}

Independent Scholar. PhD in Communication Sciences - Universidade do Vale do Rio dos Sinos / Guest Researcher at the Centre for Digital Cultures - Leuphana Universität Lüneburg.

http://orcid.org/0000-0002-8517-0206

edluersen@gmail.com

Paper submitted: 29th November 2020

Accepted for Publication. 26th April 2021

Published online: $9^{\text {th }}$ June 2021 


\begin{abstract}
The present article discusses how speculative design relates to technoscientific extrapolation, an important science fiction feature, to plan for potential scenarios and prototype viable models of futurity. Through it, the paper outlines some important nuances between different approaches concerning speculative design's role, considering their particular epistemological assumptions. A specific case is presented and discussed: Daleko (2020), a project developed for the Strelka Institute's Terraforming program. This project consists of nine science fiction pieces that entangle issues of waste management, technical infrastructure, and climate politics, discussing the problematic conception of waste as a form of externality and imagining future scenarios for managing it through a more holistic perspective. By analysing Daleko's approach to speculative design, in its final section the article suggests further developing speculative projects in contexts of design education. This would serve towards stimulating designers to ponder how their craft relates to anthropogenic impact and how it can play a decisive role in prospecting more viable future scenarios.
\end{abstract}

Keywords: speculative design; science fiction; design education; anthropogenic climate change; waste management; design and geopolitics. 


\section{Introduction}

According to philosopher Isabelle Stengers (2014), science-fiction novels can be thought of as 'the myths of today'. But apart from being catalysers for the imagination of thousands of unknown readers, science fiction stories are hands-on, inventive, and adventurous thought experiments as they demand imagining potential practical scenarios and outcomes for a particular hypothesis.

Science fiction has always been about envisioning malleable extrapolations of state-of-the-art science and technology (Shaw, 2011), a perspective that gains a deeper significance when we think about the rising pervasiveness of computer simulation and modelling in the last decades (Pias, 2011). Data sciences, statistical visualization, and scenario planning grant us the opportunity to esteem prognostic models from actual evolving states and figures, and (if combined with broad-minded political agendas) also help us to prepare for hypothetical short or long-range situations-as both the current COVID-19 pandemic and climate change issues show. Under such sombre circumstances, though, science fiction may find a renewed enthusiasm for large-scale extrapolative scenarios.

Following this perspective, a particularly important role can be reserved for speculative design (Dunne \& Raby, 2013). As a design method that explores the dormant or underdeveloped virtual possibilities of contemporary science and technology in order to address both short and long-term problems, speculative design also works on the thin line between the possible and the impossible, the acceptable and the unacceptable-much akin to science fiction. Furthermore, like the most convincing sci-fi tales, speculative design projects may be more vibrant whenever their programs can be potentially connected to the fabric of active political, economic, and social contexts (Peloušková, 2020).
In this article, we explore the intersections and disjunctions between speculative design and science fiction throughout the analysis of a specific design project developed for the Terraforming program at Strelka Institute for Media, Architecture and Design: Daleko (2020). This project repurposes the concept of waste apropos demanding alternative ways for its management in a viable future. Daleko questions the usual narrative that perpetrates waste as a form of externality, reimagining its deep-time endurance as an inevitable part of the planetary metabolism. The project encompasses nine short sci-fi pieces situated in urban and rural settings, and explores the interconnectivity between these narratives in their shared futurity.

When theorizing about Daleko, one could recall Gabriel Tarde's 1896 novel, Fragment D'histoire Future (2018), in which science fiction is intertwined with philosophical anthropology through the gaze of a fictitious historian from the future who describes the Earth in retrospect, in the aftermath of a climate catastrophe. Working in a different register, though, speculative design can not only help us imagining forthcoming planetary conditions, as also stimulate us to rethink the field of design and its potentialities in light of the geological and geopolitical implications of the Anthropocene. Thus, in the final section, we underscore the significant potential of speculative design for design education. As a pedagogical tool, we argue that it may encourage aspiring designers to ponder the problems, objectives, and implications of their projects according to a deeper time scale (Parreno, 2020), sensibly attuned to the pressing crises of our time.

\section{Speculative ways of designing}

Although this article does not intend to provide an extensive account of the many different approaches to speculative design and design fiction, it may be important to start our argumentation by briefly presenting some general lines of thought 
on these concepts in order to better delineate how they might relate to science fiction works.

The rapidly growing literature on design fiction shows just how widely it is open to several different interpretations, ideologies, and aims (Markussen \& Knutz, 2013). While Bruce Sterling's seminal definition of design fiction as 'the deliberate use of diegetic prototypes to suspend disbelief about change' (Sterling, 2012, n.p.) is extensively repeated, and sets a valid common ground to most of its variations, the following sentences of his pivotal description show perhaps an aspect of design fiction that is still very much up for dispute. According to Sterling, using diegetic prototypes means that 'you're thinking very seriously about potential objects and services and trying to get people to concentrate on those rather than entire worlds or political trends or geopolitical strategies. It's not a kind of fiction. It's a kind of design. It tells worlds rather than stories' (Sterling, 2012, n.p.).

While it is very easy to agree that prototyping diegetic objects and services has been a common goal for several different initiatives interested in fictionalizing design, we can also see how the development of background stories-even (and perhaps especially) when imagining entirely controversial contextual contingencies - seems to provide fictional plans with more space for actual, material consummation. Because products and services are easy targets for fetishization, planning with more substantial background scenarios tends to get us towards deeper implications, even when designing a fictional product or service.

Furthermore, there are several design fiction conceptions that wilfully seek to merge design with storytelling by emphasizing the narrative potentialities of diegetic prototypes in film production, for instance. This is something Julian Bleecker (2009) has been arguing for long now. In his view, diegetic prototyping concerns processes where the speculative realities become nearly tangible experiences, where the future projection in film and audiovisual stories may allow not only the envisioning of different devices and artefacts, but also a prospective imagination of how they might relate with particular social and political values. Therefore, intersecting design fiction with drama is interesting for it makes us imagine inhabitable everyday world scenarios.

Aside from the most obvious choice of filmmaking, Bleecker (2017) also suggests that diegetic prototyping can be conveyed through different media, such as repair manuals, quick start guides, or product catalogues. We could add gamification models or fake documentaries to this list as well. There are also prototypes in the form of 'accidental fictions' (Dunne \& Raby, 2013, p. 89), such as patents and failed inventions. One can recall the well-known article that Thomas Edison (1878) wrote for North American Review a year after his patent for the phonograph had been issued. There, Edison suggests future uses for the newly invented device, such as assistance in dictation, letter-writing, language preservation, as well as derived products, such as aural clocks, phonographic books, and musical toys (Luersen, 2014). Aside from the widespread adoption of mechanical sound reproduction as a medium for home entertainment during the $20^{\text {th }}$ Century, other applications that Edison imagined back then are nowadays merging with present-day technologies.

Regularly, in the unexpectedly quotidian future contexts, speculative products and services might just not work the way designers first imagined them while prototyping. Some designers even consider embedding potential errors and malfunctions to the imagined forthcoming situations as an integral part of design fiction projects. This is in fact not only a way of making the project more tangible diegetically, but also a means to further explore the non-diegetic aspects and functions of the prototype. This sort of experience is enacted in projects like Near Future Laboratory's short film A Digital Tomorrow (2012), in which a facial recognition interface malfunctions when the user is not wearing her more casual makeup, for instance. 
Such appraisal of the actual implementation of these projects is also an important matter of dispute in different accounts on speculative design, especially in what concerns the distinctions between more pragmatic and more idealistic approaches. According to Anthony Dunne and Fiona Raby's (2013) program for speculative design, projects do not have to be oriented towards providing necessarily feasible solutions. Instead, they should focus on probing new perspectives corresponding to different individual values, beliefs, desires, or social ideals. In their view, speculative ways of designing should 'emphasize imagination over practicality, and ask questions rather than provide answers. The value of the project is not in what it achieves or does but what it is and how it makes people feel' (Dunne \& Raby, 2013, p. 189). This description underlines their focus on the emotional and affective dimensions of design when providing artefacts for exhibition (as one can also notice by the very frequent use of the terms 'viewer' and 'audience' in their work). The objects, while presented in galleries, schools and museums, should primarily stimulate the imagination of the audience, inspiring them to create their own models of alternative realities. When stating that speculative design projects do not have to commit to solutions or 'improvements', and that designers should suspend this kind of judgment because 'the viewers can make up their own minds' (Dunne \& Raby, 2013, p. 189), they are openly aligning their perspective to a contemporary conceptual art paradigm. Dunne \& Raby are arguing for the designing of critical models to be experienced by the public with the main goal of potentially engaging them with the idealized proposal of the project.

While this openness concerning the work's objective-as well as the nurturing of our critical awareness about everyday design-is certainly significant to learning, imagining, and thinking about design in general, it is also important to note how this perspective relates to and contrasts with other approaches to speculative design. If we believe that 'speculative design props do not stand in for the real thing [...]; they are physical fictions, departure points for sophisticated imaginings never meant to be viewed as "real," or to reflect reality' (Ibid., p. 92), the possibility for speculative projects to participate in more enduring interventions gets radically diminished. Even if we value how aesthetic experiences stimulate our critical awareness and provoke us to question our everyday relationship with design, speculative design projects do not have to be necessarily occupied with generating only idealistic representations. With this in mind, we wish to outline what the models can accomplish whenever they openly engage in the certainly ambiguous task of outweighing the imagination and idealization divide by adopting a more rigorous technical, political, and scientific imagination in their design briefs. This is not meant to support a naïve sense of realism, but to urge us to reconsider how the models that we create can be entangled with complex material realities. By imagining the deepest epistemic issues which constitute a given 'prospective reality'-with the heterogeneous set of assumptions, regulations, moral precepts, scientific statements, organizational practices, and discourses that constitute it-a designer can nourish these projects with still imaginative yet potentially viable plans altogether. Thus, speculative prospection has a very important role to play in what extends beyond phenomenological encounters with imaginative objects. Highly imaginative models can also be derived from prosthetic conditional possibilities of forthcoming realities in their still open and ingenious constitutive aspects, as we wish to demonstrate later by presenting the Daleko project.

Again, this does not mean arguing in favour of turning the speculative model into something real in some naïve senseyet, some perspectives on speculative design would not content themselves with celebrating and experiencing projects with 'little desire to become "real"' (Ibid., p. 89). Neither would complex visions of speculative design be concerned with the general, appealing notion of 'future prediction', very popular in common sense reasoning concerning futuristic fiction. This would be a very short-sighted goal to speculative design 
projects, meaning they would be aiming for cause-and-effect inferences when imagining the space between the now and then. Instead, our argument for the engagement of speculative design with a more rigorous degree of pragmatism goes the other way around: envisioning the parameters of future realities in their abstract futurity towards providing an effective plan for working from there to our present-day conditions. This in itself becomes a method to make designers involved in developing a more enduring, substantial, long-termed yet still imaginative, design practice as a whole.

An approach more decisively imbued with a sense of pragmatism would hold the conjectural advantage of prescribing scenarios of real design articulation with actual and alternative polities, standards, regulations, and other organizational forces of society while still operating in a speculative manner-it would still produce a non-commonsensical hypothetical model in the end. Although this is not meant to be an undisputed claim, we see it as a particularly virtuous perspective for speculative design, especially when dealing with scenarios linked to the Anthropocene and the major issues and dilemmas that encompass the actual stage of biochemical life on Earth. As a concept related to the impact of the human species and our industrial capacity on the whole planet, definitions of the Anthropocene as a proper geological era often include 'the various violations of environmental and human life in corporate practices and technological culture that are ensuring that there won't be much of humans in the future scene of life' (Parikka, 2014, p. 6). In the last couple of centuries, we have transformed the cycle of interglacial periods and ice ages, something that we would have expected to change only with the accidental alteration of the axis of rotation of the planet (Archer, 2009). ${ }^{1}$ To conceive this situation where spatial and temporal scales far exceed our individual perception, an approach to speculative design that balances radical technoscientific abstraction with imagining future possibilities of actual material conformation is very welcome, if not utterly necessary.

A prominent program that tries to entangle technoscientific knowledge production and questions concerning the Anthropocene with speculative design (while shaping its own vision of it) is Strelka Institute's The Terraforming program. 'Terraforming' is a term more often heard in science fiction stories and science communication contexts, referring to the hypothetical process of modifying the atmosphere and topography of other planets and celestial bodies in order to make their ecosystems inhabitable for Earth-dwelling life forms. Strelka Institute's program, though, refers to the terraforming of planet Earth. Reflecting the perspective of program coordinator Benjamin Bratton (2019), it alludes to both the terraforming that has taken place on our planet during the past millennia, and to the terraforming that must be planned from now on as a planetary design initiative to prevent future large-scale disasters. The program emphasizes that a plan to attenuate the effects of anthropogenic climate change should take place with decisive anthropogenic response, by reconciling with artificiality through design analysis and intervention.

1 Humans are artificially interacting with the environment since the sapiens appeared around 300,000 years ago. Before the end of the last ice age 12,000 years ago, though, human populations were comparatively very small and came close to extinction several times (Veiga, 2014). Humans only stabilized with the settling of nomadic peoples when agriculture was invented. While there is still much debate concerning the exact beginning of the Anthropocene epoch, for the purpose of this essay we emphasize the most recent period of significant increase of anthropogenic impact upon the Earth's geology and ecosystems, predominantly in mid-20th century. This corresponds to the accelerating pace of energy consumption and greenhouse gas emissions demanded to power the infrastructure and logistics of increasing globalization (which is unlikely to reverse). Besides its evident moral, human dimension (Chakrabarty, 2018), the Anthropocene extends beyond human cognition, as a chronostratigraphically defined paradigm shift, a geological record of the Earth made visible by the Earth Systems Science. Approaching the subject in its geological dimension is decisive, and we should consider the bigger picture if we are to foster a proper planetary way of thinking. 
According to Bratton, if 'the future' was an aspiration to be achieved for most of the 20th century, now that planetary-scale computation provides technically measurable and foreseeable scenarios of coming global climate catastrophes, the future becomes something to be prevented. In this sense, the main task of speculative design in the Terraforming program is planning how to prevent 'one future so that another might, with luck, come to pass instead: achieved because prevented' (Bratton, 2019, p. 38). With this set of principles, the design research conducted at the institute invests a lot of energy in imagining governing infrastructures that may operate on much deeper timescales than our daily necessities and impulses.

This is a perspective that catalyses Bratton's previously declared views on speculative design:

Instead of concluding that the future (and futurism per se) is lost we should commandeer modelling infrastructures for better and more vibrant purposes. For this, speculative models are rotated from one purpose to another: less to predict what is most likely to happen (deriving value from advance simulation of given outcomes) than to search the space of actual possibility (even and especially beyond what any of us would conceive otherwise.) That is, predictive models are adaptive because they need to be descriptive, but for speculation, models are prescriptive because they need to become normative. (Bratton, 2016, n.p.)

Adopting this angle means investing a lot of energy in grounding the epistemological foundations over which the speculative projects' premises will be drawn upon. In our view, this is how design theory and prototyping can merge for more programmatically enriching speculation. Contrasting with views of producing more seemingly nearby products and services, such a standpoint favours the more ambiguous (and thus, more 'vibrant') imagination of a whole tectonics of design-a fissure in the actual normal conditions of possibility that becomes a condition for potential normalizations. This is precisely the reason why science fiction works that explore the very ambiguity of future scenarios can foster more meaningful insights for their extrapolative scenarios. When disengaged from retrieving deeper structural conditions, speculation runs the risk of becoming no more than a fetishization of our actual present-day ideals.

As Klára Peloušková (2020) affirms, Bratton's remarkably abstract plan may seem suspiciously ambitious, but it has little to do with more spectacular forms of speculative design, which tend to be primarily concerned with providing allegorical representations. The perspective outlined by the Terraforming program encompasses an obsession with scientific and philosophical materialism, speculating on the assembly of novel normal megastructures, while still considering their ambiguity and uncertainty. The suggestion of emerging norms and values enables its technoscientific extrapolative scenarios to remain interwoven with a high degree of political self-awareness.

We can see how this works by describing and analysing one of the developed projects from the Terraforming design research program. This analysis will also provide a glimpse on how the project entangles some specific aspects of science fiction and speculative design.

\section{Daleko: entangling design and science fiction}

Daleko is one the final projects of the first year of the Terraforming program. The project was developed by Eleanor Peres, Anastasia Sinitsyna, Tigran Kostandyan, and Tim Nosov. They propose nine science-fiction illustrated prose stories centred on sites of obsolescence in post-Soviet rural and urban territories. The stories are told in the form of graphically animated fragments illustrated in the manner of late-Soviet 
cartoon aesthetics, with the drawings graphically exploring a rich mix of biochemical, cartographic, cosmological, and technoscientific motifs. The anachronistic graphic style seems to match the purpose of interlacing different temporal phases in the storylines, and this sense of experiencing a more stretched time lapse is interesting because it resonates with the idea of inquiring the temporalities of waste cycles, as explored in the project.

Integrating with Bratton's approach to speculative design, Daleko suggests that alternatively to the current solutions for dealing with disposability cycles, such as circular economy, the coming planetary scenarios also require larger-scale and longer-term plans. Daleko acknowledges this necessity by revisiting the concept of waste itself. The project elicits that our usual notion of waste as a form of exteriority is rooted in a fictive perspective: an imaginary outside towards which all wasted matter must go. The common understanding that discarded materials will eventually simply disappear in any sort of junkyard (becoming waste) is associated to its disappearance from quotidian sight. This imagined exteriority is, though, often defined by very unsurprising economic and geopolitical arrangements, as the current flows of electronic residues from developed to developing countries demonstrate (Gabrys, 2011; Parikka, 2015). As Ioana Jucan argues, 'the outmoded does not go away-it only goes elsewhere' (Jucan, 2019, p. 12). Still, the perspective unfolded by Daleko takes this statement further by exploring its geochemical condition. Interiorization and externalization are understood as expressions of a preceding culture-nature divide. The regulatory designation of landfills, junkyards, or dumping grounds as places cultivated for disposal provides a testimonial image of a usual short-sighted perspective on the geochemical processing of matter. The geotechnical arrangement of these sites contributes to shaping the enduring fictive imagination of waste as something external. Thus, in the long run, other ways of collecting and accommodating exceeding matter must be designed. This is why in Daleko the question concerning waste is reimagined by primarily replacing its conception as external for a more holistic comprehension. Instead of leftovers, we get to know about matter folding matter, a planetary metabolism of processable physicochemical materials. The dynamic terrestrial metabolic cycles are entangled with artificial, manufactured, anthropogenic, and yet still earthbounded matter. Under this deeply materialist view, ambitious mega-scale projects are intertwined with a perspective programmatically concerned with the deep scales of geological time.

In the following pages we summarize the nine stories that comprise the Daleko project, highlighting the relationship between the fictional scenarios within the projects and technoscientific extrapolation. This is an important aspect to consider because extrapolation is a remarkable characteristic of science fiction. We do not discuss any of the stories in greater detail, prioritizing analysing the whole project with a broader scope. ${ }^{2}$ Getting a general notion of the central aspects of each of these stories provides us with a compressed perspective to discuss further in this section how speculative design research can benefit from a pragmatic approximation to technoscientific knowledge in general, and to science fiction extrapolations more specifically.

The tale Moscow Garbage Ring deals with the imagery of periphery, and shows how our practices of disposal are entangled with this notion. Informal work dominates the management and traffic of waste across borders. We learn that landfills in Russia occupy an area the size of Netherlands. Around $80 \%$ of domestic waste is sent to landfills, and what is left is usually incinerated. In this tale we read about the experimental revitalization of the town of Pushchino, one of the peripheral landfill areas of Moscow. In the future, the 'Ministry

2 Of course, we recommend that the interested reader access the complete Daleko project: <https://daleko.space/>. Accessed: 2 February 2021. 
of Technical Aesthetics' approves a pilot program according to which all waste should be properly reevaluated as secondary raw materials or fertilizers, reducing in $70 \%$ the waste in the town. Garbage chutes and specific types of package are also banned in the city, pushing companies to develop technologies for reprocessing raw materials. This hypothetical norm is inspired by a 1960s ecological movement led by local scientists of Pushchino. In the story, the town becomes a national reference for its confluence between sustainable initiatives and research in molecular and chemical biology. The Moscow Garbage Ring is turned into a half-wild park, known for its hybrid landscapes that combine the newborn biomes with conserved centuries-old architecture. Its eco-agricultural ethos includes well-known approaches, such as permaculture, aquaponics, and slow food, but also innovations derived from reprocessing petrocultural commodities.

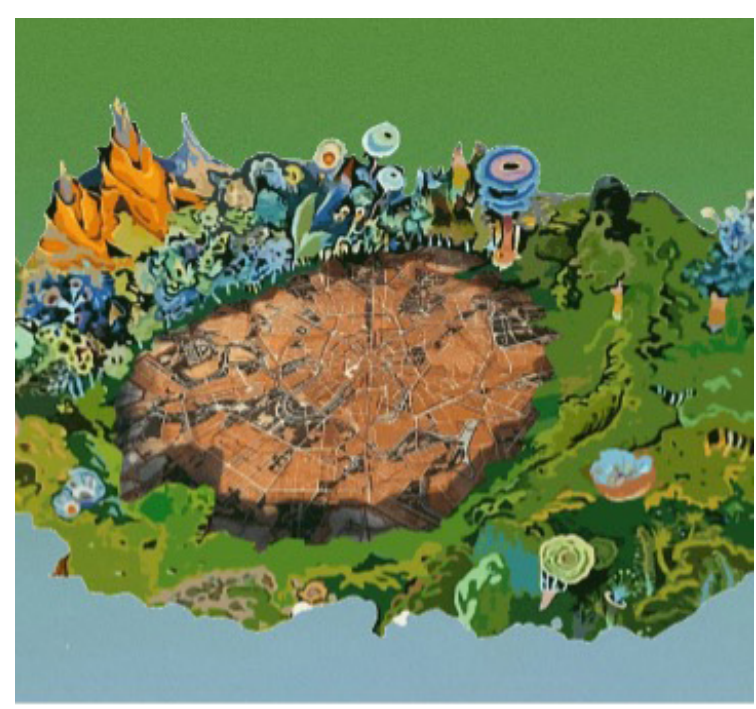

Fig. 1 Illustration from the Moscow Garbage Ring story ${ }^{3}$

Another story, Flight Path Zapovednik, explores how the conceptual externalization of waste can locally affect very specific biomes and populations, especially when coupled with a short-sighted view of development. The story dives into the historical case of the Kazakh steppes as a sacrificed zone that saw its biodiversity drastically diminish in a few decades. The installation of the Baikonur Cosmodrome in the 1950's turned the area into the largest spaceport in the world, as well as a testing ground for ballistic missiles. In a matter of few years, the toxic fuel of rocket launches degraded the wildlife, livestock, and communities explicitly along the flight path. The fiction piece addresses this case by elaborating a project that entangles ecological caretaking practices, technoscientific environmental control, and international relations with a nomothetic approach. We are shown a plan for an alternative remodelling of the region as a natural reserve in coming years: after decades of pollution caused by weapon debris in the Kazakh steppes, Russia renegotiates a debt of the former URSS with Kazakhstan through a new pact to 'phytoremediate' the area under the flight path. The rapidly rising temperature in Russia also presses the government to invest in funding this infrastructure, which operates through a live database that communicates between paid native 'caretakers, heat-sensing infrared satellite imagery and distributed data centers' (Peres et al., 2019). With this arrangement, the area becomes the first protected landscape on the planet to combine contemporary sensing technologies with indigenous practices of managing land by means of a transnational project.

The next story approaches the purported 'outer space', the most extreme imagined boundary to an outside. Rebirth Orbit connects future initiatives with present-day space waste management experiments. It refers to the information that currently $90 \%$ of the objects in orbit are space junk, a consequence of decades of unregulated spacecraft abandonment and satellite disposal. The story imagines a space program that not only launches satellites into orbit, delivering astronauts and new equipment to the cosmos, but also collects

3 From Peres, E., Sinitsyna, A., Kostandyan, T., \& Nosov, T. (2020). Daleko. Strelka Institute for Media Architecture and Design. https://daleko. space/. 
space junk, releasing it into flammable zones of the atmosphere. Technically, this program is openly based on initiatives like RemoveDEBRIS ${ }^{4}$, and the projects to upcycle space debris developed by Studio Roosegaarde's Space Waste Lab, which seek to turn waste into shooting stars or use it as a source material for 3D-printed structures on the moon. The cosmic cleaning accomplished with garbage rockets, as proposed in Rebirth Orbit, does not extrapolate the technical ideas already developed by current space labs as much as it extrapolates its governing structures: in the tale, controlled re-entry, spacecraft retirement and waste collecting are all regulated by new international agreements and transnational services concerning the commonly shared problem of space debris.

Deep Sekretiki deals with the problem of waste in regard to extrativism and the colossal infrastructure developed to provide planetary-scale oil supply. This story is particularly interesting because it presupposes the understanding of Earth as a metabolic system, where sensory organs (monitors) guide and regulate the ratio between digesting and expelling. It imagines the repurposing of two complementary, already existing, gigantic infrastructures: one used nowadays for commercial satellite control and military operations, repurposed to monitor carbon emissions and methane leakage horizontally, while informing regulatory agencies; and the other the wide network of oil extraction pipelines, repaired and retro-engineered to perform carbon capture and storage. These decades-old infrastructures are known to have low energy efficiency and, as underground armatures, are hidden from sight. The speculation within the project involves turning these deeply buried structures of oil extraction visible and measurable, providing a parameter for keeping leakage and emission levels under the established goals of regulatory agencies. This again involves a broader organizational setting, with the future foundation of a 'Planetary Emissions Sensing Unit' (PESU) responsible for not only monitoring but also publicizing the largest global data sets about the ongoing effects of climate change. The PESU 'presents' the Russian government with the profoundly compromising climate-crime statistics involving the reckless yet quotidian oil bleedings, and the fossil fuel industry owners are required under federal law to meet the annual international sensing standards, keeping emissions under the established limit of $20 \%$. This story is especially interesting for entangling data sciences, climate journalism, and geoengineering in a same imaginary multi-institutional project.

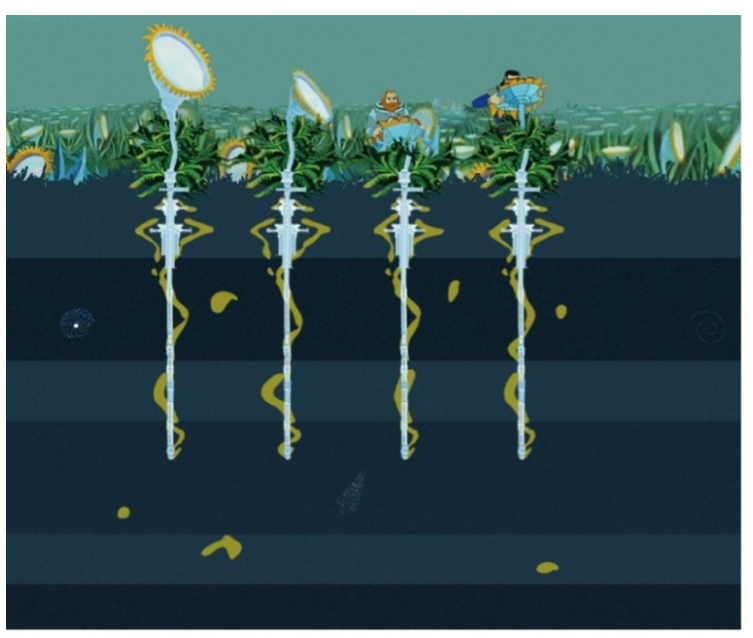

Fig. 2 Illustration from the Deep Sekretiki story ${ }^{5}$

The peculiar Nuclear Ikea plot is narrated by an autonomous artificial intelligence system (to call it a 'first-person narrative' would perhaps be inadequate) that is responsible for surveilling, managing, and regulating the used nuclear fuel stored

4 RemoveDEBRIS is a research project that seeks to test potential space debris removal technologies. Its mission is to demonstrate various Active Debris Removal technologies on prototype targets in low Earth orbit. The experimental platform structure is equipped with nets, harpoons, laser altimeters, and miniature satellites.

5 From Peres, E., Sinitsyna, A., Kostandyan, T., \& Nosov, T. (2020). Daleko. Strelka Institute for Media Architecture and Design. https://daleko. space/. 
inside a Deep Geological Repository, ${ }^{6}$ km down into the underground of the Nizhnekamsk massif in Russia. This story imagines a time when fossil fuel is no longer the dominant global energy source. The development of a new generation of fast, modular neutron reactors allows the planetary spread of nuclear power reactors and the large-scale reutilization of spent nuclear fuel. Computation, automation, logistics, and geoengineering are rendered together in the form of a service to store and manage the used nuclear fuel imported from inside and outside the Russian territory. Although the story does not get into details, it seems to speculate about two important underlying preconditions for this hypothetical situation: the development of a transcontinental network for logistical management and transportation of nuclear waste, and the restructuring of labour in dangerous working conditions around non-human, computational agents. ${ }^{\text {? }}$

River in Death Valley deals with the case of Khalmer-Yu, a former urban settlement established for coal mining from the 1940s to the 1990s. In the last decades, the area has been turned into a military test site for bombs and other weapons. In Daleko, this region does not function as a weapon testing ground anymore. Instead, it becomes a test site for scientific experiments in climate change mitigation, generating labour to local and visiting workers. The military airport becomes the laboratorial area from where aircrafts depart to perform stratospheric aerosol injection. Sensing units are deployed to measure temperature, air composition, and solar reflectance. At the same time, the local knowledge of citizens is used to comprehend the results of anthropogenic impact on the land, flora, and fauna. In effect, we can state that an interesting parallel idea in this piece is the repurposing of the concept of testing ground: the transformation of the environmentally-costly weapon test site into a climate change-related geoengineering research facility suggests a local experiment to be scaled up in order to mitigate the effects of global warming

One important issue with the manner we conceive the problem of waste in our everyday lives is in understanding the specific problem of discarding as a matter of individual action. This reasoning is counterproductive since individual responsibility only accounts for a slight portion of the problem, as we tend to ignore the complexity of the situation. To be able to account for the wider dimension of this subject, a more effective way of tracing the transcontinental flow of solid residues is necessary. As pointed in a previous study (Luersen \& Fuchs, 2021), notable environmental organizations such as the Basel Action Network attempt to exceed themselves at inventing idiosyncratic monitoring strategies. ${ }^{8}$ Yet, with the persistence of irregular discarding, but also wildfires, and deforestation, we need to make use of the potential cutting-edge monitoring tools and networks that we already have available. The tale Black Sky Coordinates explores this situation by suggesting the coupling of neural network models, environmental crime prevention units, and our personal phones to provide an instrument for publicly monitoring, identifying, and informing the levels of air pollution of a given area. By nurturing the public interest and providing adequate instruments for the technical sensing of pollution, the project probes a nomothetic outcome measure, with both the right to have clean air and the right to access up-to-date reliable information about local pollution being assured, in coming years, by the Russian constitution.

6 A Deep Geological Repository (DGR) is a planned disposal facility composed by a network of subterranean tunnels and placement rooms within a stable geologic layer in the deep underground, where high level or semi-long term nuclear waste should be stored and isolated for a period of thousands of years.

7 Perhaps this story provides a good example why Julian Bleecker's advice to embed potential errors in speculative projects is very timely While there are often many anxieties in the public opinion when debating the prospects of nuclear waste management, speculative design can remind us that in large-scale technological projects, contingencies should be considered accordingly.

8 These include, for instance, sneaking trackers and installing hidden cameras into waste skips and containers to trace and monitor irregular discarding and traffic of toxic scrap metal inside and across borders (Hopson \& Puckett, 2016; Baldé et al., 2017). 


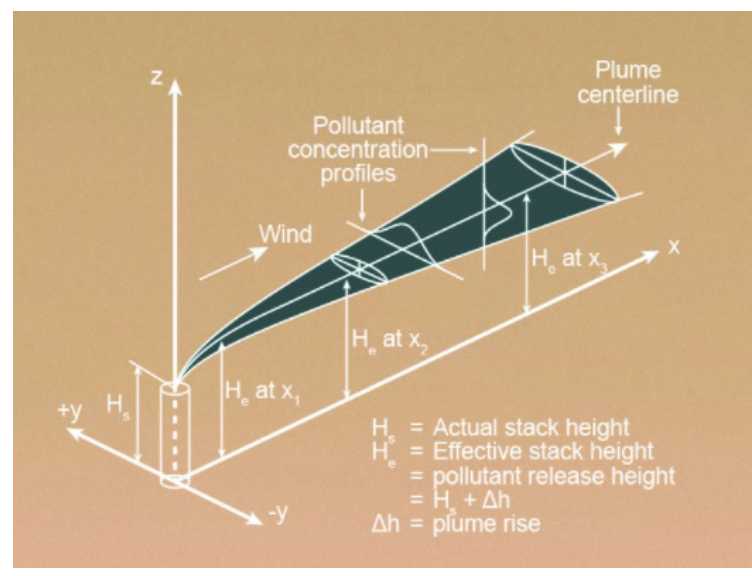

Fig. 3 Illustration from the Black Sky Coordinates story ${ }^{9}$

The fragment Oceanic Swarm begins with a familiar statement concerning our still highly limited knowledge about the space of the deep sea. The project repurposes the abandoned Aniva lighthouse, an ancient tower (once used to assist in ship navigation) that ran obsolete with the development of Global Positioning System (GPS) technology. In this story, the lighthouse is repurposed into the Aniva Station: a technical facility that receives acoustic information collected by swarms of Autonomous Underwater Vehicles and transmits it to a set of interconnected satellites. The future station is imagined as an essential node for the integration of communications between the biosphere, hydrosphere, and technosphere as a long-term viable data feedback system. The sound signals captured by the swarms provide updated information regarding sea conditions (its temperature, salinity, density, and degree of pollution) to a wide network of marine biology and oceanography institutes involved in global climate observation. The project also suggests a relation between the task of monitoring the sea and gaming, describing the analyst scientist as sort of an 'avatar in an ocean-world computer game, searching out signals of environmental distress' (Peres et al.,
2020, n.p.) while also exploring the still unknown regions of the ocean bed.

While the former story approaches the substantially unknown space of the sea with curiosity, Copernican Dive envisions a plan to deal with the amount of matter that is widely known to be routinely dumped into the oceans. The project informs us that Russia dumps 13,000 tons of plastic waste into the sea every year. Palaeobiologists state that the cumulative amount of plastic produced as of 2015 was already enough to wrap the whole world in plastic film (Zalasiewicz et al., 2015). As the whole discussion on the 'Plasticene' (Haram et al., 2020) unravels, the current recycling policies and regulations do not suffice to prevent much of this plastic matter of ending up into the oceans. Copernican Dive's plan considers ecological, but also technical, legal, geopolitical, and economic implications involved in the problem of plastic disposal. This tale foresees that in the near future the problem of dumping plastic into the sea will receive as much media coverage and attention as the fall of debris of the MIR Space Station into the Pacific Ocean did in 2001. The project infers that the mass disposal of waste effectively comes to be regarded as a political issue of commons in the future, thus becoming subject to the scrutiny of the international community. In light of the impending climate catastrophe, the global economy begins to be restructured around environmental issues, with scenario simulation and geochemical modelling playing an important monitoring role. With the possibility of strictly parameterizing and evaluating the environmental damage of different ecological disasters on a planetary scale, the responsible parties start to be held legally accountable before the international community, turning oceanic waste dumping too costly.

One of the decisive aspects in the short stories presented in Daleko is that technological extrapolation seems to prospect its plan with a background of multipolar geopolitical economy

9 From Peres, E., Sinitsyna, A., Kostandyan, T., \& Nosov, T. (2020). Daleko. Strelka Institute for Media Architecture and Design. https://daleko. space/. 


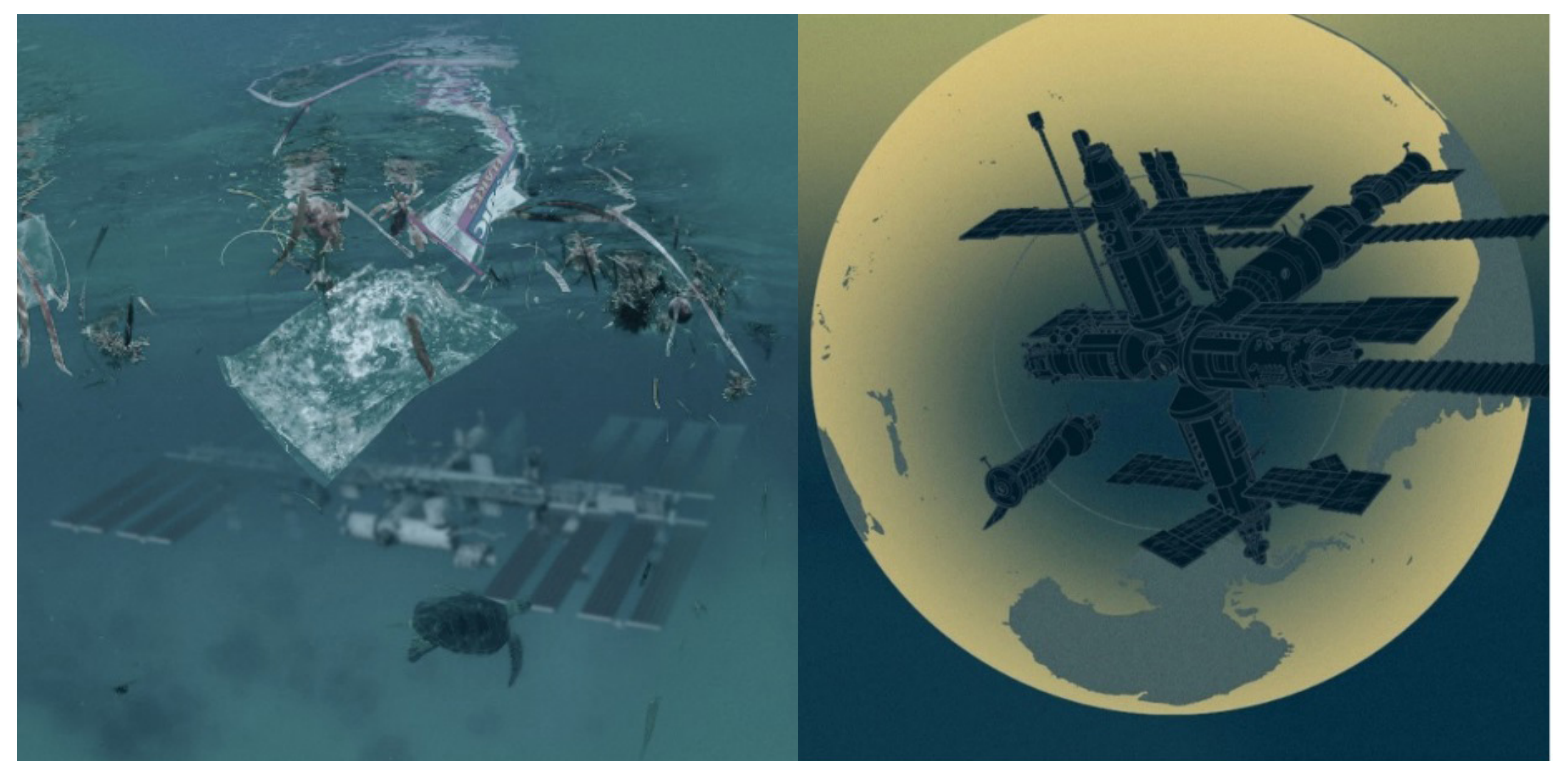

Fig. 4 Illustrations from the Copernican Dive story ${ }^{10}$

in mind. Despite the high degree of uncertainty that pervade foreign affairs at the present moment, the recent events in global politics signal a growing awareness about the urgent need to mitigate the effects of climate change. With the apparent alignment of China, European Union, and (just very recently) the United States with the Paris Agreement, and with markets leaning towards green initiatives, this agenda is likely to be more directly involved in multilateral commercial treaties and international affairs as an impending climate governance power, as suggested by economic historian Adam Tooze (2020). In his view, even if the potential new climate power politics does not result in a consolidated consensual vision among sovereign states, companies and corporations that might be seen as a threat to climate stability may be in danger of losing their license to operate. In this scenario, political interventions conjoined with laws, rulings, and regulations are more likely to happen.
In the week before Xi Jinping's speech to the UN, Climate Action 100 Plus, a lobby group whose members represent global investors with a collective $\$ 47$ trillion in assets, announced that it would be judging 161 of the largest companies, collectively responsible for up to 80 percent of global industrial greenhouse gases, by their progress towards net-zero carbon emissions by 2050. Of course, there is an element of corporate greenwashing in any such statement. But it can also be read as a vote by giant asset managers like BlackRock and Pimco against escape. Like Beijing, they agree that the status quo and the future accumulation of capital depends on maintaining a stable environmental envelope. (Tooze, 2020, p. 7)

Daleko's design plans are always intermingling with jurisdictional and geopolitical implications, even if the length of the

10 From Peres, E., Sinitsyna, A., Kostandyan, T., \& Nosov, T. (2020). Daleko. Strelka Institute for Media Architecture and Design. https://daleko. space/. 
short stories does not provide enough room for an in-depth unfolding of its fictional developments. While it may be accurate to say that most designers usually do not share a profound interest in economics, law, and international politics, exploring these issues through speculative design projects represents a very significant opportunity to insert the agenda concerning the Anthropocene more deeply into design research and education. And the same goes for the other way around: inquiring into the Anthropocene grants us an opportunity to build a more robust (and very urgent) ground for design research.

Here again speculative design can nurture from science fiction. Imagining future realities demands envisioning different background assumptions according to which societies and cultures explain their living conditions. Speculative design can imagine the habits, gestures, commonalities, and discontents that the interaction with extrapolated technologies might stimulate or restrain, prompting reflection on potential projects as well as fostering tentative procedures for their actual development.

Daleko also demonstrates that intermingling design with science fiction today should not mean necessarily reenacting the most established tropes of the latter. On the contrary, its most experimental models could nurture from an intensive engagement with state-of-the-art scientific developments. This is not so different from what the so-called 'hard science fiction' always did, and in this case it would demand a renovated interest in different scientific enterprises by design researchers. For the case of challenging the waste issue in the Anthropocene, Daleko accomplishes it by diving into recent research themes from the fields of Geology, Biochemistry, Astronomy, Marine Biology, Robotics, Computer Sciences, Geoengineering, Ecology, and Agriculture, to name a few.

With this in mind, one could argue that the science fiction stories proposed by Daleko would be tied to a teleological view on scientific and technological progress. In our understanding, though, it suggests otherwise: that technological development is not a straight line, and in light of the anthropogenic impact on Earth, it is the task of designers to embrace artificiality with the long-durée of geotechnical conformations, but also the instability of techno-political arrangements in mind. As philosopher Bernard Stiegler (as cited in Dunker, 2021) would put it, technologies are both poisonous and curative. For the sake of making them curative, their uses and practical possibilities have to be managed and restrained. For long the regulatory power of sovereign states has been responsible for organizing them. Nonetheless, it is everyday clearer that if the nation-states continue to struggle due to global economic and cultural processes, in the coming years we will be forced to discover or invent different forms of control over technology and its effects. With increasing demand for food and different sorts of soft and hard goods, extraction, consumption, and discarding are naturally not scaling down. Engaging seriously with artificial initiatives is a necessary part to invent viable, coordinated forms of coexistence. Extrapolating technologies might become actually redesigning them while organizing their normalization. The engagement of speculative design and science fiction in Daleko rests over a planning imagination that exercises a feedback loop between these two instances: normalization of extrapolations, and extrapolation of normalizations.

In this sense, one could be tempted to relate the future world imagined by Daleko to the aesthetics of solarpunk (Schuller, 2019; Springett, 2017), a literary and artistic movement that tries to counter the sombre visions on technological development by proposing alternative sustainable scenarios. Solarpunk science-fiction intentionally opposes the rather bleak foundations of steampunk and early cyberpunk aesthetics by trying to produce 'more optimistic science fictions'. Pertinent critiques have been made to the enthusiastic optimism of solarpunk (Raven, 2020; Zuin, 2020), especially regarding an 'uncriticalness' in assessing scientific practices, a passive 
compliance towards innovation, or simply unrestrained techno-utopianism. Daleko's future settings can be certainly related to solarpunk imageries, but this does not prevent the project from exploring complex and pragmatic arrangements between technoscientific regulation, policy makers, and governmental platforms. On the contrary, most of the fragments correspond to scenarios where the technoscientific milieu intersects with rather familiar agents of governance-precisely because the project seems to embed the current crises of our established political institutions in its driving subtext. The tales attempt to envisage possibilities for a different, even if more abstruse, scenario instead of the more regularly imagined utopic or dystopic destinations that contemplate either an ideal accommodation or a complete disruption of viable forms of future coexistence.

It certainly sounds more promising than our usual tendency to fictionalize future scenarios in the form of a dreamland-doomscape duality, as it instead allows for exploring the subtle ambiguities and actual sloppiness that more often than not characterize our relationship with technological development. The nine fragments of Daleko all look closer to solarpunk aesthetics than the usual apocalyptic scenarios; nevertheless, it would be misleading to think of them as relying on utterly idealistic, utopian scenarios. As we understand it, this is due to its commitment to a more materially-oriented extrapolation, as much as its particular view on speculative design, as outlined in the previous section of this paper. Therefore, it is important to consider what the nine fragments accomplish in these short provocative pieces while exploring several technical and jurisdictional limitations. This is important because it leaves its imagined future scenarios up to dispute and thoroughly undecided.

What is at issue, then, is how speculative design could be able to contrive deeply materialist yet imaginative models of futurity. Contrary to what one might think on a first glimpse (and Daleko helps us in overcoming this impasse), this may not mean pushing for a whimsical detachment from norms and regulations, but plunging into a rationalized engagement with their techno-political substance. This may entice the projects to speculate over ingenious, even if ambiguous, scenarios of normalization. We can see how this modulation is revealing of the particular approach by the Terraforming program to speculative design as something that should still rely on necessity. Something that is not unconstrained, but rather pragmatic in the sense of 'identifying the parameters of what's needed and then working back from there to today, and being as open as necessary about what means might realize those ends' (Bratton, 2021 , n.p.). While programmatically extrapolating current deadlock situations concerning technology and governance, Daleko couples its imagined future infrastructures with this sense of pragmatism, considering that these design assemblages could push a chain of additional extrapolations in urban and rural settings. It provides us with alternative images to discuss the role of design when it comes to issues of waste management and climate change mitigation, for instance. This alone is a good enough reason to advance this research agenda further, given that we already have plenty of data, images, estimations, and projections of future worlds where the adverse effects of the Anthropocene are not addressed.

Furthermore, the project fulfils an important epistemological function towards stimulating designers to ask questions concerning not only abstract future settings but also very material possibilities of our present technological milieu-both fundamental issues for design theory and practice (Luersen, 2020). Thus, we believe that projects as Daleko reveal an important merit of approaching speculative design as a method in design education contexts, an issue that we would like to address in our concluding section.

\section{Speculative design in educational contexts}

Engaging with science fiction-like technological and jurisdictive extrapolations contribute to the speculative assignment 
of imagining preventable and achievable futures for our environments. However, by doing this, speculative design projects also stimulate thinking about what will the role of design be in these prospective milieus. This is an entry point for understanding design not only as a specialized craft, but also in its wider epistemological scope, with substantial ramifications in organizational practices, public management, and even in issues of governance and sovereignty. In this sense, as Dunne \& Raby identify, '[a] speculative design proposal can also serve as a "probe" for highlighting legal and ethical limits to existing systems' (2013, p. 57). This is a particularly enticing opportunity to discuss what would be the role of design in such limits, but also in modelling alternative systems with its own prospective, embedded limitations. As it turns out, the question of how all these issues intermingle is very desirable in contexts of design education. In terms of using design expertise for dealing with the multidimensional problems of a complex world (Cardoso, 2016), where local and global-scale problems often intersect, speculative design becomes an interesting method for disciplines of project planning. It can spark important questionings about the discipline when adopted in the production of briefings and prototypes.

When facing the urgency of taking collective action on issues related to the Anthropocene, such as climate change, it is not enough for the field of design to have theoretical discussions without deliberating programmatic agendas for action-just as it is not enough, of course, to act without proper philosophical and ethical foundations. As Anders Dunker (2021, p. 4) puts it, we have to follow the old pedagogical advice of learning how to learn, indeed, but this must be supplemented. Serious action should be taken by truly exploring the endogenous and exogenous obstacles to climate policies. Besides, if the natural sciences inform us regarding crucial factors of the environmental crisis, and in turn allow us to estimate future scenarios in varied forms of scientific projections, it is also true that the practical mitigation of global climate change effects can only take place with the adoption of different anthropotechnical practices. If it is indeed correct that we need to discover or invent adequate ways to live together with other species (Haraway, 2016) in damaged or ruined landscapes of our planet (Tsing, 2015), the speculative alternatives must go beyond the rhetorical sphere of moral speeches we tell each other, and materialize in a gradual rooting of this knowledge in our continued practice. These questions are already starting to pervade public opinion, but this alone will not suffice. To properly permeate living practice, they must surpass the discursive layer, penetrating established disciplines. In terms of design education, this means incorporating the knowledge of Earth and space sciences about environmental crises, for instance, into the projects we undertake, engaging the practice of design with the broader dynamics of geomorphic manifestations. To accept this challenge as designers we must do what we do-artificially arrange matter-while also rigorously combining technical and theoretical practice. The only chance that we have of effectively incorporating this knowledge into continuous design habits (design culture) is by embedding it into planning and prototyping right from our pedagogical practices. Whether applied to activities in the public or private sectors, this is a way to undermine the conception of design as a carefree, short-span exercise and to properly reevaluate it with regard to the actual artificial layer of the planet for which it is largely responsible. As Cristina Parreño (2020) conjectures, a shared superficial understanding of time alienates us from the deep-time consequences of our anthropogenic action on Earth. What is at stake when designing industrial products, choosing a set of materials, developing techniques, or planning novel infrastructures is much more than short-term solutions. To believe so would be to forget the anthropotechnical history of our species.

Therefore, in parallel to learning how to plan and shape things and services, the adoption of speculative design as a method in design pedagogy can offer an opportunity to critically assess the potential future responsibilities of our field in the 
long run. Design education for longer-term projects has to necessarily frame the theoretical and professional competences of design in connection to different experiments in scientific and sociopolitical settings. We would like to highlight that the approach to speculative design discussed here and described with the case of Daleko is particularly significant in this context, due to its rigorous embrace of a materialist perspective and its perception of the catalytic effects of design on society. This means understanding the wide range of materials and technical means through which we may artificially implement large-scale projects, but it also requires prospecting how such alternatives may further support, undermine, retrofit, or rearrange conventions, agreements, and regulations. Technologies for sensing ecosystems, monitoring emissions, advancing crop rotation, reusing materials, renewing energy, restoring biomes, etc. all have a role to play in the composition of viable future scenarios of interdependence. We can see, though, that while they are far from being underdeveloped per se, these techniques are unsatisfactorily integrated with normative common-interest aspects of our daily lives. From industrial automation and machine learning to genetic engineering, from pervasive computing to networked remote sensing systems and cloud manufacturing, the different design disciplines may find an assorted range of distinctive materials to cope with. In order to turn their promising contributions into something that is collectively beneficial and effective in the long term, designers should not refrain from exploring the potential amalgamation of speculative projects with more enduring entities of society, such as political institutions, public agencies, platforms of governance, civil society organizations, and so on. This is pedagogically relevant because it may compel designers to be somewhat less self-referential in order to face the material possibilities of our current technological milieu with both an extrapolative imagination and yet a pragmatic commitment at hand.

With this is mind, we can also conclude that designing speculative projects like Daleko in contexts of design education contributes to reshaping and updating urgent questions regarding design decisions and their resulting programmatic functions in hypothetical and experimental assemblages. Here we emphasize the term 'experimental' because planning such extrapolative worlds provides a possibility to engage in particularly difficult, curious, ambiguous, or even uncanny questions that we would not ask ourselves otherwise. Here, our more commonplace moral impasses should not refrain, but instead provoke our aspirations to model. The more a project allows us to explore the ethical, legal, and practical thresholds of design objects, services, and programs, the more it may be suited to explore the actual and virtual roles of design together with students and researchers. In Daleko, this is more clearly illustrated by the Nuclear Ikea story, since dealing with nuclear technology as an energy source is still regarded as taboo among several environmental traditions, or even in common sense. How should designers engage with these discussions? What could we learn for our practice from studying the science behind nuclear-powered energy sources? What are the technical and non-technical aspects that we should take into account when planning involves nuclear energy? What are the potential implications of using nuclear power generation for energy efficiency, and what could be their collateral environmental consequences? How such implications and consequences should underlie multilateral agreements? How should energy management infrastructures be designed to interact with not only actual, but also potential international norms and regulations for viable forms of future coexistence? Questions tend to rise in complexity along with the building process of speculative projects.

With this in mind, we can think of speculative design as an important discipline for different degrees of design education, since probing imaginative future scenarios helps in setting the conditions to ponder prosaic yet fundamental practical questions involved from the early stages of design briefing to the prototype's afterlife, unravelling the density of these questions throughout the way. 


\section{Final considerations}

While some authors argue that speculative design should enable designers to counter the constraints that define normative design processes (Auger, 2016), in this paper we have contended that an alternative possibility for fiction within design would instead try to understand such constrains and imagine how our speculative projects could intermingle with them (as well as with potentially uncontrolled, unmannered, if not completely accidental, collateral scenarios). In the convergence between anthropogenic and non-human, intentional or accidental developments, new normative processes will emerge. Regardless of our sentiments towards them, promising and compromising normative dimensions are intrinsic to design, and we should therefore openly explore this condition in educational contexts as an enriching pedagogical prospect.

We are aware that among the several different approaches to speculative design, some may be more inclined to disprove such normative dimension, and therefore adopt a prima-facie refusal of discussing it in its merit. But this is precisely why we argue that such a perspective is important for design education and research. We can assume that the somewhat endemic crises that entangle neoliberal economies, state sovereignty, and climate upheavals will not naturally attenuate, as they all amalgamate in a huddle of different procedural timescales and conflicting priorities. Our composing disciplines, normative apparatus, and our own personal commitments will all have to dedicate a lot of energy for issues of restoration, regeneration, and retro-engineering. Under these circumstances, developing the ability to conduct our projects considering a longer time span and a stricter material frame will be vital even for speculative planning, if we desire that future infrastructures, hypothetical regulations, and further interventions dare to contemplate any degree of resilience. In this scenario, the perspectives provided by the science fiction fragments of Daleko are of utmost significance: if we understand the conceptual problem of treating waste as a form of externality, and instead start reimagining its deeptime endurance as part of a larger planetary metabolism, we can prototype divergent patterns and scenarios. Under the geochemical approach of waste as matter folding matter, our projects, laws, treaties, and technical interventions should account for viable (and necessary) ways of managing energy as more than resources to be consumed and discarded indefinitely.

Summarily, this takes us to acknowledge that entangling design and science fiction throughout a speculative approach that considers actual material conditions, technological assemblages, and their interfacing with governance norms and regulations can help us imagining more enduring interventions. Like science fiction, our most rewarding speculative projects extrapolate from the realms of state-of-the-art scientific knowledge, concepts, and theory to constructively build back from the future to the present without refraining from testing boundaries and posing uncomfortable questions.

\section{References}

Archer, D. (2009). The Long Thaw: How Humans Are Changing the Next 100,000 Years of Earth's Climate. Princeton: Princeton University Press.

Auger, J. (2016). Interviews: Discourse. In: Mitrovic, I., \& Šuran, O. Speculative - Post-Design Practice or New Utopia? Zagreb: Ministry of Culture of the Republic of Croatia \& Croatian Designers Association.

Baldé, C. P., Forti V., Gray, V., Kuehr, R., \& Stegmann, P. (2017). The Global E-waste Monitor. Bonn/Geneva/Vienna: United Nations University (UNU), International Telecommunication Union (ITU) \& International Solid Waste Association (ISWA). https://www.itu.int/en/ITU-D/Climate-Change/Documents/ GEM\%202017/Global-E-waste\%20Monitor\%202017\%20.pdf. 
Basel Action Network. (2018). The 'Scam Recycling' Continues: E-Waste Exportation from the U.S. to Developing Countries (Update \#2). https://wiki.ban.org/images/1/17/ScamRecyclingContinuesUpdate_2.pdf.

Bleecker, J. (2009). Design Fiction: A Short Essay on Design, Science, Fact and Fiction. Los Angeles: Near Future Laboratory.

Bleecker, J. (2017, November). Stanford Seminar - Design Fiction. [Video]. https://libguides.murdoch.edu.au/APA/social_ media.

Bratton, B. (2021). Benjamin H. Bratton on Terraforming the World Order. Palladium. https://palladiummag. com/2021/01/11/benjamin-h-bratton-on-terraforming-the-world-order/.

Bratton, B. (2016). On Speculative Design, Dis Magazine, The Time Complex: Postcontemporary Issue. http://dismagazine.com/discussion/81971/on-speculative-design-benjamin-h-bratton/.

Bratton, B. (2019). The Terraforming. Moscow: Strelka Press.

Cardoso, R. (2016). Design para um mundo complexo. São Paulo: Cosac Naify.

Chakrabarty, D. (2018). Anthropocene Time. History and Theory, 57(1), pp. 5-32.

Dunker, A. (2021). Rediscovering Earth: Ten Dialogues on the Future of Nature. New York: OR Books.
Dunne, A., \& Raby, F. (2013). Speculative Everything: Design, Fiction, and Social Dreaming. Cambridge: MIT Press.

Edison, T. A. (1878). The Phonograph and its Future, North American Review, 126(262), pp. 527-36.

Gabrys, J. (2013). Digital Rubbish: A Natural History of Electronics. Ann Arbor: University of Michigan Press.

Haraway, D. (2016). Staying With the Trouble: Making Kin in the Chthulucene. Durham and London: Duke University Press.

Hopson, E., \& Puckett, J. (2016). Scam Recycling: E-Dumping on Asia by US Recyclers. http://wiki.ban.org/images/1/12/ ScamRecyclingReport-web.pdf.

Jucan, I. (2019). Introduction: Remain X Remain(s). In: Jucan, I., Parikka, J., \& Schneider, R. Remain. Lüneburg: Meson Press.

Haram, L. E., Carlton, J. T., Ruiz, G. M., \& Maximenko, N. A. (2020). A Plasticene Lexicon. Marine Pollution Bulletin, 150 [Jan. 2020]. https://doi.org/10.1016/j.marpolbul.2019.110714.

Luersen, E. H. (2014). Comunicação, Indústria Fonográfica e Tecnologia: A Jornada do Artista Autônomo Através dos Novos Caminhos da Produção Musical. Saarbrücken: Novas Edições Acadêmicas.

Luersen, E. H. (2020). Ressonância Tecnocultural: Rastros da Ambiência Contemporânea nas Sonoridades dos Jogos Digitais [Doctoral Dissertation, University of Vale do Rio dos Sinos]. Repositório Digital da Biblioteca da Unisinos. http://www.repositorio.jesuita.org.br/handle/UNISINOS/9316. 
Luersen, E. H., \& Fuchs, M. (2021). Ruins of Excess: Computer Game Images and the Rendering of Technological Obsolescence. Games and Culture: A Journal of Interactive Media. Advance Online Publication. doi. org/10.1177/15554120211005363.

Markussen, T., \& Knutz, E. (2013). The Poetics of Design Fiction. In: Proceedings DPPI '73. ACM, New York, pp. 231-240.

Near Future Laboratory (2012, August 25). A Digital Tomorrow. [Video]. https://vimeo.com/48204264.

Parikka, J. (2015). A Geology of Media. Minneapolis: University of Minnesota Press.

Parikka, J. (2014). The Anthrobscene. Minneapolis: University of Minnesota Press

Parreño, A. (2020). Deep Timescales of Our Most Urgent Crises, Strelka Mag, The Revenge of the Real Issue. https://strelkamag. com/en/article/deep-timescales-of-our-most-urgent-crises.

Peloušková, K. (2020). Lesk a Bída Spekulativního Designu, Artalk Revue, April. https://artalk.cz/2020/04/27/lesk-a-bida-spekulativniho-designu/cs/\#_ftnref14.

Peres, E., Sinitsyna, A., Kostandyan, T., \& Nosov, T. (2020). Daleko. Strelka Institute for Media Architecture and Design. https:// daleko.space/.

Pias, C. (2011). On the Epistemology of Computer Simulation. Zeitschrift für Medien und Kulturforschung, 2(1), pp. 29-54.

Raven, P. (2020, April 9). Necessary but not Sufficient; On Hope and Optimism in Solarpunk and Cyberpunk. Velcro City. https:// www.velcro-city.co.uk/necessary-but-not-sufficient-on-hopeand-optimism-in-solarpunk-and-cyberpunk/.
Schuller, W. K. (2019). 'Evolution Takes Love:' Tracing Some Themes of the Solarpunk Genre. [M.A. Thesis, Queen's University]. QSpace. https://qspace.library.queensu.ca/bitstream/ handle/1974/26518/Schuller_William_K_201909_MA.pdf?sequence $=2 \&$ isAllowed $=y$.

Shaw, D. B. (2011). Technoculture: the Key Concepts. London: Routledge.

Springett, J. (2017, February 26). Solarpunk: A Reference Guide. Solarpunks. https://medium.com/solarpunks/solarpunk-a-reference-guide-8bcf18871965.

Stengers, I. (2014). Gaia, the Urgency to Think (and Feel). In: Colóquio Internacional os Mil Nomes de Gaia: do Antropoceno à Idade da Terra. Casa de Rui Barbosa, Rio de Janeiro. PPGAS Museu Nacional UFRJ. Sep. 15-19, 2014. https://osmilnomesdegaia.files.wordpress.com/2014/11/isabelle-stengers.pdf.

Sterling, B. (2012). Bruce Sterling Explains the Intriguing New Concept of Design Fiction (Interview by Torie Bosch). Slate. http://www.slate.com/blogs/future_tense/2012/03/02/ bruce_sterling_on_design_fictions_.html.

Tarde, G. (2018). Fragments d'Histoire Future. New York, Wentworth Press.

Tooze, A. (2020). After Escape: The New Climate Power Politics. E-Flux, 174[Dec. 2020], n.p.

Tsing, A. (2015). Mushroom at the End of the World: On the Possibility of Life in Capitalist Ruins. Princeton: Princeton University Press.

Veiga, J. E. (2014). O imbróglio do clima: Ciência, Política e Economia. São Paulo: SENAC. 
INTERNATIONAL JOURNAL OF FILM AND MEDIA ARTS (2021) Vol. 6, №. 1

Zalasiewicz, J., Waters, C. N., Sul, J. I., Corcoran, P. L., Barnosky, A. D., Cearreta, A., Edgeworth, M., Gałuszka, A., Jeandel, C., Leinfelder, R., McNeill, J. R., Steffen, W., Summerhayes, C., Wagreich, M., Williams, M., Wolfe, A. P., \& Yonan, Y. (2015). The geological cycle of plastics and their use as a stratigraphic indicator of the Anthropocene. Anthropocene, 13[Mar. 2016], pp. 4-17.

Zuin, L. (2020, November 26). 'Vai Dar Ruim:' Além da Estética, Distopias são Advertências sobre Futuro. UOL TAB. https:// tab.uol.com.br/colunas/lidia-zuin/2020/11/26/distopias.htm 